“ (C) 2019 IEEE. Personal use of this material is permitted. Permission from IEEE must be obtained for all other uses, in any current or future media, including

reprinting/republishing this material for advertising or promotional purposes, creating new collective works, for resale or redistribution to servers or lists, or reuse of any copyrighted component of this work in other works." 


\title{
Torque Analysis and Dynamic Performance Improvement of a PMSM for EVs by Skew Angle Optimization
}

\author{
Zhou Shi, Xiaodong Sun, Senior Member, IEEE, Yingfeng Cai, Zebin Yang, Gang Lei, Member, IEEE, \\ Youguang Guo, Senior Member, IEEE, and Jianguo Zhu, Senior Member, IEEE
}

\begin{abstract}
In this paper, a permanent magnet synchronous machine (PMSM) for electric vehicles (EVs) is studied. Since EVs need to face some low speed road conditions, it is necessary to drive the machine to maintain a stable torque at low speed. The stator skew slot is often adopted to reduce torque ripple; however, it declines the output torque at same time. Besides, the difference between positive rotation performance and negative rotation performance which caused by the skew slot are often ignored. Through the finite element analysis (FEA), the cogging torque and dynamic performance of the PMSM at different skew angle are studied. Moreover, the different influence of slot skew angle on positive and negative rotation performance is studied. Then the optimum skew angle of the PMSM is studied through comprehensive consideration. Finally, the cogging torque of the prototype is verified to be less than $2 \mathrm{~N}$.m. through the experiment.

Index Terms-electric vehicles; finite element analysis; skew angle; torque ripple
\end{abstract}

\section{INTRODUCTION}

With the rapid development of the new energy industry, new energy vehicles, especially electric vehicles (EVs) are attracting more attention from the society and government. The development of EVs mainly depends on the development of battery, electric control, and electric machine technology. As the only power source of pure electric vehicle, the development of electric machine technology is particularly important.

Manuscript received July 4, 2018; revised October 17, 2018 and January 5, 2018; accepted November 15, 2018. This work was supported by the National Natural Science Foundation of China under Projects 51875261, U1564201, U1664258, 61601203, and 61403172, the Natural Science Foundation of Jiangsu Province of China under Projects BK20180046 and BK20170071, the "Qinglan project" of Jiangsu Province, the Key Project of Natural Science Foundation of Jiangsu Higher Education Institutions under Project 17KJA460005, the Six Categories Talent Peak of Jiangsu Province under Project 2015-XNYQC-003, the Key Research and Development Program of Jiangsu Province under Project BE2016149, the "333 project" of Jiangsu Province under Project BRA2017441, the Postgraduate Research \& Practice Innovation Program of Jiangsu Province under Project KYCX17_1815. (Corresponding author: X. Sun.)

Z. Shi, X. Sun, and Y. Cai are with the Automotive Engineering Research Institute, Jiangsu University, Zhenjiang 212013, China (shizhoujiangda@163.com xdsun@ujs.edu.cn, caicaixiao0304@126.com).

G. Lei, Y. Guo, and J. Zhu are with the School of Electrical, Mechanical, and Mechatronic Systems, University of Technology Sydney, Sydney, NSW 2007, Australia (e-mail: Youguang.Guo-1@uts.edu.au, Gang.Lei@uts.edu.au, jianguo.zhu@uts.edu.au).

Z. Yang is with the School of Electrical and Information Engineering, Jiangsu University, Zhenjiang 212013, China (e-mail: zbyang@ujs.edu.cn).

Color versions of one or more of the figures in this paper are available online at http://ieeexplore.iee.org.

Digital Object Identifier will be inserted here upon acceptance.
As the permanent magnet synchronous machines (PMSMs) have the characteristics of high power density and high efficiency, PMSMs are the most attractive drive machine among all types of machines $[1,2]$. In order to improve the dynamic performance of PMSMs a large number of studies have been carried out [3-5].

However, the torque ripple of permanent magnet machine at low speed is still urgent to be solved. The main solutions to reduce the torque ripple are suitable permanent magnet structure design, well matching of pole and slot numbers, and skew-slot order to reduce the cogging torque and torque ripple of the permanent magnet machines, a lot of research has been carried out [6-8]. The main measures are using unequal thickness permanent magnets, adopting the auxiliary slot, and adopting skew-slots [9, 10]. Skew slot is the most effective way to reduce the cogging torque, however it will sacrifice the output torque. Moreover, when the skew angle is not equal to the slot angle, the influence of the skew angle on the positive and negative dynamic performance is different. Due to the frequent switching direction of the $\mathrm{EV}$ machines, the positive and negative dynamic performance needs to be studied separately when studying the optimal skew angle.

The purpose of this paper is to improve the dynamic performance of a PMSM for EVs and select the appropriate skew angle for the PMSM. Firstly, parameter matching of the machine is given in part II and a 24/8-pole PMSM is adopted for the study. Secondly the treatment method of skew slot in by 2D-equivalent finite element analysis (FEA) model is put forward and verified. Then, the relationship between the torque ripple and the skew angle is investigated in details. The positive rotation performance and negative rotation performance of the PMSM under different skew angle is studied. Finally, an appropriate skew angle is chosen for the proposed machine.

\section{PARAMETER MATChING OF The MACHINE}

An EV was designed for the daily use in Zhenjiang. The speed and torque requirements were investigated for this EV application by recording the road condition. The highest torque demand, good voltage regulation over wide-speed generation, and the demand for maximum speed are the primary design parameters $[11,12]$. The parameter values of the test $\mathrm{EV}$ are given in Table I. The rate power and the machine speed can be calculated from these values. 
TABLE I

Miniature Battery EV Parameters

\begin{tabular}{ccc}
\hline \hline Parameters & Symbol & Value \\
\hline Total mass of the EV & $M$ & $900 \mathrm{~kg}$ \\
Rolling friction coefficient & $f$ & 0.015 \\
Final drive fixed gear ratio & $i_{\text {diff }}$ & 8.83 \\
Front cross sectional area & $A$ & $2.1 \mathrm{~m}^{2}$ \\
Radius of wheel & $R$ & $275 \mathrm{~mm}$ \\
Air drag coefficient & $C_{\mathrm{D}}$ & 0.34 \\
\hline
\end{tabular}

Fig. 1. Structure of the PMSM

TABLE II

MAIN PARAMETERS OF THE PMSM

\begin{tabular}{cc}
\hline \hline Phase number & 3 \\
Pole number & 8 \\
Slot number & 24 \\
Stator outside diameter & $154 \mathrm{~mm}$ \\
Rotor diameter & $101 \mathrm{~mm}$ \\
Shaft diameter & $31.5 \mathrm{~mm}$ \\
Air-gap length & $0.5 \mathrm{~mm}$ \\
Core length & $129.5 \mathrm{~mm}$ \\
PM dimensions & $4.81 \times 30.5 \times 134 \mathrm{~mm}^{3}$ \\
Turns per slot & 80 \\
Permanent magnet material & NdFe35 \\
Lamination material & DW465-50 \\
\hline
\end{tabular}

The drive force will keep balance with the total resistance force and when run at a constant speed. And the output power of drive machine will keep balance with the sum of resistance power and system loss power. So the drive torque $\left(T_{\mathrm{tq}}\right)$ and power of the machine $\left(P_{e}\right)$ can be expressed as follow

$$
\begin{gathered}
\frac{T_{\mathrm{tq}} i_{\mathrm{g}} i_{0} \eta_{T}}{r}=G f \cos \beta+\frac{C_{\mathrm{D}} A}{21.15} u_{a}^{2}+G \sin \beta \\
P_{\mathrm{e}}=\frac{1}{\eta_{T}}\left(\frac{G f u_{a}}{3600}+\frac{G u_{a} \cos \beta}{3600}+\frac{C_{D} A u_{a}^{3}}{76140}\right)
\end{gathered}
$$

where $\eta_{\mathrm{T}}$ is the system efficiency of drive system, $i_{g}$ and $i_{0}$ are the transmission ratio and deceleration ratio respectively, $G$ and $f$ are the total gravity of the EV and rolling friction coefficient respectively, $C_{D}$ is the air drag coefficient, $\beta$ and $A$ are the angle of slope the front cross sectional area, respectively. In the case of having $P_{e}$ and $u_{\mathrm{a}}$, the rotational speed $(n)$ requirements of machine at a certain $u_{\mathrm{a}}$ can be given by.

$$
u_{a}=0.377 \frac{r n}{i_{g} i_{0}}
$$

The initial design parameters of PMSM can be obtained by calculating the vehicle driving power and the speed of the drive system above mentioned. A PMSM with 24 slots and 8 poles is designed for this research which is shown in Fig.1 and main parameters of the machine are given in Table II. Here $\alpha$ is used to represent for the skew angle which is measured in mechanical angle. To improve dynamic performance of the PMSM, some dynamic characteristics will be analyzed by FEA mainly includes the analysis of the winding back electromotive force
(EMF), the flux linkage, the cogging torque, and the output torque. The effects of the skew-slot on the motor characteristics will be summed up by comparing the characteristics under different skew angle.

\section{TREATMENT OF SKEW SLOT IN 2D-FEA MoDEL}

The common method for calculating the performance of a PMSM is the three-dimensional finite element analysis (3DFEA). However, since 3D-FEA needs a large amount of calculation and a long period, the efficiency of this method is relatively low when the slot angle needs accuracy optimization.

In this study a two dimensional finite element analysis (2DFEA) calculation method of segmented slot is adopted. The concrete method is to divide the machine into $N$ section along the axial average, and calculate each segment approximately as a straight slot to calculate the magnetic chain and magnetic co energy in each section of the rotor at different angles of the rotor $[13,14]$. Then the winding flux linkage and the magnetic flux of the each section are separately added to replace a skew slot structure. The equivalent flux linkage and equivalent magnetic flux are written as

$$
\left\{\begin{array}{l}
\psi_{\mathrm{A}}=\frac{N_{\mathrm{ph}} \cdot L_{\mathrm{ef}}}{N} \sum_{i=0}^{N-1} \phi_{\mathrm{A} i} \\
\phi_{\mathrm{A} i}=A_{A 2 i}-A_{A 1 i}
\end{array}\right.
$$

where $\Psi_{A}$ is the equivalent flux linkage of the phase $\mathrm{A}, N_{\mathrm{ph}}$ is the number of conductors, $L_{\mathrm{ef}}$ is the motor depth, $\Phi_{A i}$ is the magnetic flux on unit length of phase A. $A_{\mathrm{A} 2 \mathrm{i}}$ and $A_{\mathrm{A} 1 \mathrm{i}}$ are the magnetic vector potential of the $i$ part of the PMSM. The equivalent electromotive force (EMF) of the machine can be calculated from (5)

$$
e_{A e q}=-\frac{\omega}{N} \frac{d \psi_{A i}}{d \theta} \approx-\omega \frac{N_{\mathrm{ph}} \cdot L_{\mathrm{ef}}}{N}\left(\sum_{i=0}^{N-1} \frac{\phi_{A 2 i}-\phi_{A 2 i}}{\theta_{A 2 i}-\theta_{A 1 i}}\right)
$$

where $\mathrm{e}_{A e q}$ is the equivalent electromotive force, $\theta_{\mathrm{A} 2 \mathrm{i}}$ and $\theta_{\mathrm{A} 1 \mathrm{i}}$ are the rotor position degree of the $i$ part of the PMSM,

In order to verify the effectiveness of this method, a typical model at $\alpha=7.5^{\circ}$ is selected to compare 2D and 3D simulation results. Fig. 2 gives the 2D and 3D FEA model of the proposed machine. In this simulation, the $2 \mathrm{D}$-model is divided into 15 segments to simulation the flux linkage and back electromotive force of each part and then calculate of equivalent results. In the following simulation results, there is a difference between phase positions of two models, which is convenient for comparison.

The flux linkage and back-EMF simulation results of 3Dmodel and 2D-equivalent model is show in Figs. 3 and 4, respectively. The flux linkages of two models are almost the same, and there is only a little difference on the back-EMF of two models. Besides, the cogging torque results of two models are shown in Fig.5. Based on the above simulation results, it can be seen that the $2 \mathrm{D}$-equivalent model is effective and accurate for the study of the stator skew-slot, and by using 2Dequivalent model can save $80 \%$ calculation time. Therefore, 
the 2D-equivalent model is adopted in study of the best skew angle optimization.

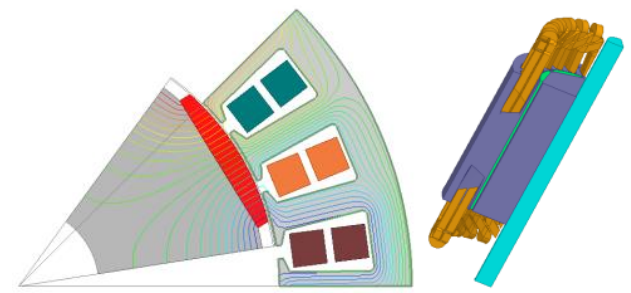

Fig. 2. 2D equivalent and 3D FEA models

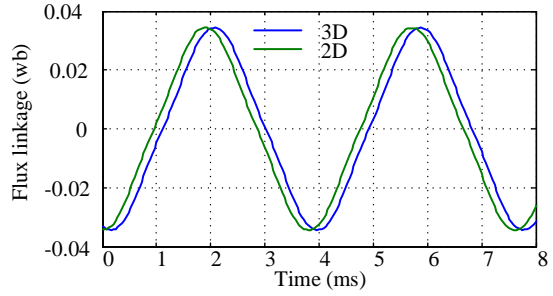

Fig. 3. Flux linkage simulation results of 3D- and 2D-equivalent models

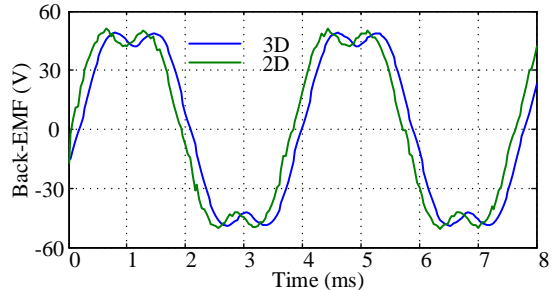

Fig. 4.Back-EMF simulation results of 3D- and 2D-equivalent models

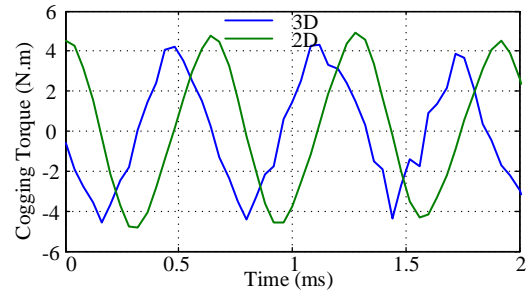

Fig. 5.Cogging torque simulation results of 3D- and 2D-equivalent models

\section{AnAlysis of Best Slot SKeW ANGLE}

In this section, the best slot skew angle of the proposed machine will be studied by using the $2 \mathrm{D}$ equivalent model. Since the prototype in this study has 24 slots structure, the optimum angle of the skew angle $(\alpha)$ is from $0^{\circ}$ to $15^{\circ}$.

\section{A. Back EMF}

The no-load back-EMFs of different skew angles are shown in Fig. 6. As shown, with the increase of the skew angle, the waveform of the back EMF is much close to the sine. However, the amplitude decreases with the increase of $\alpha$. In addition, the harmonic analysis results of back EMF at different skew angles are shown in Fig. 7 where the fundamental wave of the EMF will decrease, but the higher harmonics can also be reduced.

\section{B. Cogging Torque}

The cogging torque at different skew angles is shown in Fig. 8. As shown, the skew angle effective in reducing cogging torque. When the skew angle is equal to the slot angle $\left(\alpha=15^{\circ}\right)$, the amplitude of the cogging torque is almost $0 \mathrm{~N} \cdot \mathrm{m}$.

\section{Output Torque}

The output torque under different skew angle is shown in Fig. 9. As shown, the torque ripple can be reduced by increas- ing the skew angle. However, the output torque will be sacrificed at the same time. When the PMSM rotated in negative rotation direction, since Holzer sensor of the PMSM is installed on the single side of the machine, the effect of the skew slot on the output torque is different from that when the PMSM rotated in positive rotation direction. The positive and negative rotation output torques at $\alpha=2$ are shown in Fig. 10. As shown, the influences of the skew slot on the positive and negative rotation are different.

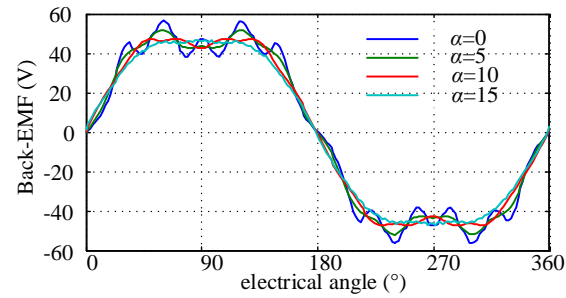

Fig. 6. Back EMF waveforms @ 4000r/min

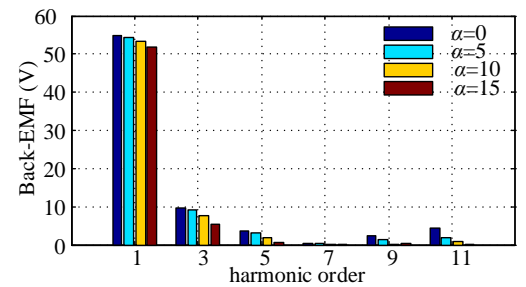

Fig. 7. Back EMF waveforms harmonic analysis @ 4000r/min

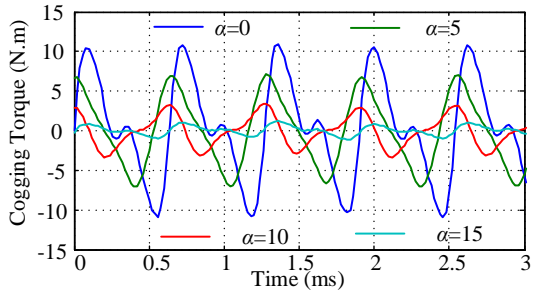

Fig. 8. Cogging torque

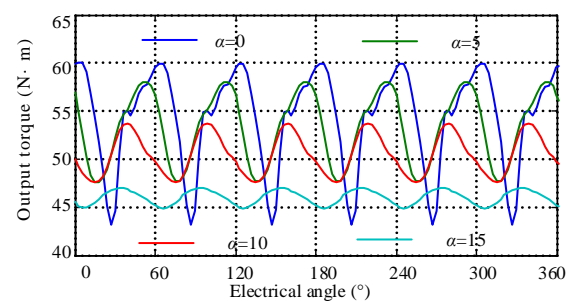

Fig. 9. Output torque

The skew slot can reduce the torque ripple and can also decline the average torque at same time. Besides, the influences of the skew slot on the positive and negative rotation are different. Thus, it is essential to find a suitable skew angle. In the optimization process, both positive and negative dynamic performance of the machine should be taken into consideration.

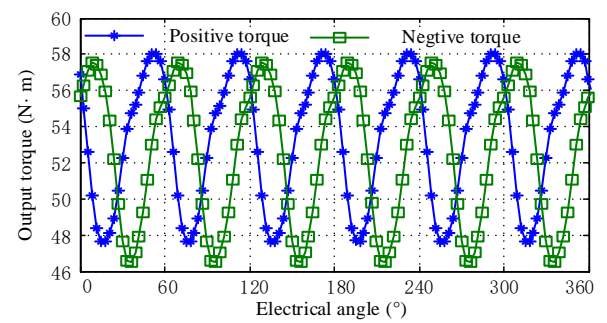

Fig. 10. Positive rotation and negative rotation output torque @ $\alpha=2$

Thus, a multi-objective optimization problem can be formulated as 


$$
\left\{\begin{array}{l}
\max :\left\{F(\alpha)=T_{\mathrm{Pave}} \cdot T_{\mathrm{Nave}} \cdot\left(P_{\mathrm{TP}} \% \cdot P_{T \mathrm{~N}} \%\right)^{-1.5} \cdot T_{\mathrm{cog}}{ }^{-1}\right\} \\
\text { s.t. }\{\alpha \in(0,15)\}
\end{array}\right.
$$

where $P_{\mathrm{TP}} \%$ and $P_{\mathrm{TN}} \%$ are the amplitude ratio of torque ripples, $T_{\text {Pave }}$ and $T_{\text {Nave }}$ are the positive and negative rotation average output torques respectively, and $T_{\operatorname{cog}}$ is the amplitude of the cogging torque. In this optimization function, the main optimization objectives are proportioned. The torque ripple and cogging torque are negative elements, so their indexes are negative. In addition, the torque ripple is the main optimization objective so its index is -1.5 . Through this optimization function, the torque ripple and cogging torque can be minimized without sacrificing too much average torque, and a relatively suitable skew angle can be found. Finally, according to the optimization equation the skew angle of the proposed machine is chosen to be $12^{\circ}$.

\section{EXPERIMENT}

In order to validate the previous studies, a prototype of the proposed PMSM is manufactured. The experiment of the cogging torque and output torque are carried out on the platform which is show in Fig. 11. The experimental results are shown in Figs. 12 and 13. The amplitude of the cogging torque of the prototype measured by the experiment is less than $2 \mathrm{~N} \cdot \mathrm{m}$ and the torque ripple of both positive and negative output torque are less than $5 \mathrm{~N} \cdot \mathrm{m}$. The experimental results certify that the optimization of skew angle is effective.

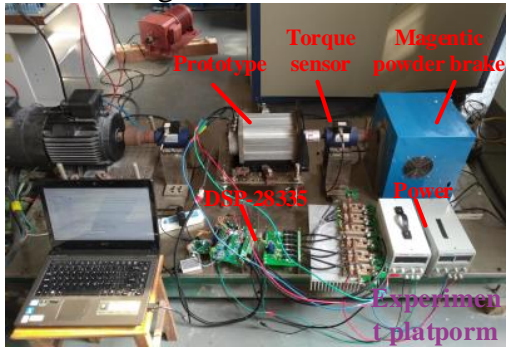

Fig. 11. Experiment platform and prototype.

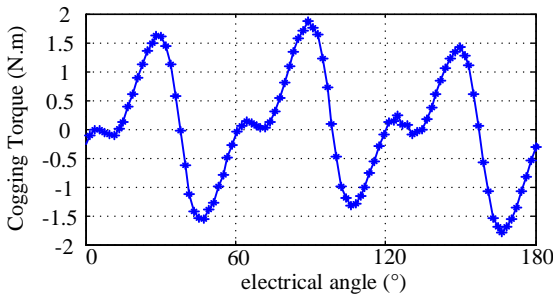

Fig. 12. Experimental result of cogging torque.

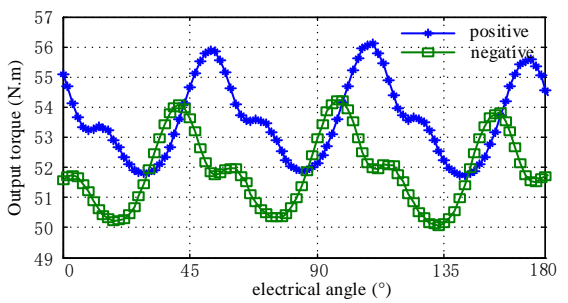

Fig. 13. Experimental result of output torque.

\section{CONCLUSIONS}

The dynamic performance of PMSM for EVs is improved in this paper by optimizing the skew angle. A 2D-FEA equiva- lent method is proposed to analyze the dynamic performance at different skew angles. In addition, the optimal skew angle is obtained by the optimization function. Through this work, the optimized skew angle can effectively improve the comprehensive dynamic performance of the machine.

\section{REFERENCES}

[1] I. Petrov, M. Niemela, P. Ponomarev, and J. Pyrhonen, "Rotor surface ferrite permanent magnets in electrical machines: advantages and limitations," IEEE Trans. Ind. Electron., vol. 64, pp. 5314-5322, 2017.

[2] X. Sun, L. Chen, Z. Yang, and H. Zhu. "Speed-sensorless vector control of a bearingless induction machine with artificial neural network inverse speed observer," IEEE/ASME Trans. Mechatronics, 3, vol. 18. No 4, pp 1357-1366, 2013.

[3] G. Lei, T. S. Wang, J. G. Zhu, Y. G. Guo and S. H. Wang, "System level design optimization method for electrical drive systems: deterministic approach," IEEE Trans. Ind. Electron., vol. 61, no. 12, pp. 6591-6602, 2014.

[4] S. G. Min and B. Sarlioglu, "3-D performance analysis and multiobjective optimization of coreless-type pm linear synchronous motors," IEEE Trans. Ind. Electron., vol. 65, pp. 1855-1864, 2018.

[5] X. Sun, C. Long, Z. Yang. "Overview of bearingless permanent magnet synchronous machines," IEEE Trans. Ind. Electron., vol. 60, pp. 5528$5538,2013$.

[6] B. S. Gagas, K. Sasaki, T. Fukushige, A. Athavale, T. Kato, and R. D. Lorenz, "Analysis of magnetizing trajectories for variable flux pm synchronous machines considering voltage, high-speed capability, torque ripple, and time duration," IEEE Trans. Ind. Appl., vol. 52, pp. 4029-4038, 2016.

[7] C. Sikder, I. Husain and W. Ouyang, "Cogging torque reduction in fluxswitching permanent-magnet machines by rotor pole shaping," IEEE Trans. Ind. Appl., vol. 51, pp. 3609-3619, 2015.

[8] S. A. Saied, K. Abbaszadeh, A. Tenconi, and S. Vaschetto, "New approach to cogging torque simulation using numerical functions,"IEEE Trans. Ind. Electron, vol. 50, pp. 2420-2426, 2014.

[9] R. P. Deodhar, A. Pride and J. J. Bremner, "Design method and experimental verification of a novel technique for torque ripple reduction in stator claw-pole PM machines," IEEE Trans. Ind. Appl., vol. 51, pp. 3743-3750, 2011.

[10] X. Sun, B. Su, L. Chen, Z. Yang, X. Xu and Z. Shi, "Precise control of a four degree-of-freedom permanent magnet biased active magnetic bearing system in a magnetically suspended direct-driven spindle using neural network inverse scheme", Mechanical Systems and Signal Processing, vol. 88, pp. 36-48, May 2017.

[11] G. Lei, J. Zhu, Y. Guo, C. Liu and B. Ma, "A review of design optimization methods for electrical machines", Energies, vol. 10, no. 12, Art. no. 1962, pp. 1-31, 2017

[12] X. Sun, Y Shen, S Wang, G Lei, Z Yang, and S Han, "Core losses analysis of a novel 16/10 segmented rotor switched reluctance BSG motor for HEVs using nonlinear lumped parameter equivalent circuit model," IEEE/ASME Trans. Mechatron.,vol. 23, no. 2, pp. 747-757, 2018

[13] G. De Donato, F. Capponi, G. A. Rivellini, and F. Caricchi, "Integralslot versus fractional-slot concentrated-winding axial-flux permanentmagnet machines: comparative design, fea, and experimental tests," IEEE Trans. Ind. Electron., vol. 48, pp. 1487-1495, 2012.

[14] X. Sun, Z. Shi, L. Chen, and Zebin Yang. "Internal model control for a bearingless permanent magnet synchronous motor based on inverse system method," IEEE Trans.s Energy Convers., vol. 31, no. 4, pp. $1539-1548,2016$ 